\title{
Case Study: Competitive Advantage at All Costs - An Inside Look at Five Pharmaceutical Industry Practices Which Undermined Customer Relationships
}

\author{
Edward P. Nathan ${ }^{1}$ \\ ${ }^{1}$ Roy H Park School of Communications, Ithaca College, Ithaca, NY, United States \\ Correspondence: Edward P. Nathan, Roy H Park School of Communications, Ithaca College, Ithaca, NY, United \\ States. Tel: 1-484-716-9565, E-mail: epnathan1@gmail.com
}

Received: November 12, 2019

Accepted: December 16, 2019 Online Published: December 17, 2019

doi:10.5430/jms.v11n1p7

URL: https://doi.org/10.5430/jms.v11n1p7

\begin{abstract}
This study attempts to answer the question: Over the past 35 years, what competitive business practices instituted by the pharmaceutical industry intended to drive increased competitiveness and business efficiencies had the unintended results of increasing the publics' general distrust and dissatisfaction with the industry? This paper takes a unique perspective by analyzing five apparently disparate business practices designed to improve business performance but which also increased customer distrust and dissatisfaction of the industry. Specifically the five business practices were:

1. Reliance on pharmaceutical marketers with MBAs but limited or no practical pharmaceutical selling experience.

2. The loss of independent pharmacies and pharmacists as customers due to the rise in national pharmacy chains.

3. Purchase and use of physician-specific prescribing data

4. Use of direct to consumer advertising for prescription drugs

5. Delaying generic competition and providing industry support for the Affordable Healthcare Act in exchange for U. S. government prohibition against the importation of low cost prescription drugs into the U.S. and prohibiting negotiated Medicare drug prices.

The paper uses a case study methodology. The results section details the practices reviewed in this case study and suggests they did improve competitiveness and efficiencies, but also contributed to erosion in customer confidence which includes key customer groups: physicians, pharmacists, patients and payers. Consumer groups such as American Association of Retired Persons (AARP) are focusing both financial resources and membership efforts to advocate for changes in pharmaceutical industry pricing and marketing practices. To see if this phenomenon has occurred in other industries, it was observed that the airlines, fast food and information technology industries also pursued greater business efficiencies. The discussion section suggests they too experienced and continue to experience significant customer relationship issues resulting from the drive for greater efficiencies, including government intervention to address customer concerns. The conclusions review some of the limitations of this study and suggest areas for additional research.
\end{abstract}

Keywords: physician, pharmacist, pharmaceutical sales, direct to consumer, retail pharmacies, drug prices, pay to delay, drug importation, pharmaceutical business practices, competitive advantage, customer relationship

\section{Introduction}

For profit businesses have an obligation to their shareholders to maximize profit by improving business efficiencies and enhancing their competitive advantage wherever possible. Using technology and tapping into newly available resources allows businesses to evolve and analyze their current operational business practices and find ways to improve them. The pharmaceutical industry is no different. Since the mid-1980s there have been numerous changes in operational business practices in the HR, information technology, sales, marketing and drug pricing functions. 
In the case of the pharmaceutical industry, the generic term "customer" utilized in this study refers to four groups of key customers: physicians, pharmacists, patients and payers.

This research study will use a case study approach as suggested by Yin (2004, pp. 21-28) to examine five apparently unrelated business practices designed to enhance competitiveness and increase business efficiency. Those five business practice are:

1. Reliance on pharmaceutical marketers with MBAs but limited or no practical pharmaceutical selling experience.

2. The loss of independent pharmacies and pharmacists as customers due to the rise in national pharmacy chains.

3. Purchase and use of physician-specific prescribing data

4. Use of direct to consumer advertising for prescription drugs

5. Delaying generic competition and providing industry support for the Affordable Healthcare Act in exchange for U. S. government prohibition against the importation of low cost prescription drugs into the U.S. and prohibiting negotiated Medicare drug prices.

What makes these five practices (which seem unrelated) of interest, is that one was implemented as a change in hiring practice by pharmaceutical marketing functions, another was driven by market research and the availability of more robust physician prescribing data. One practice resulted from events in another industry - the consolidation of the retail pharmacy space into national and regional retail chains - and the pharmaceutical industry's response. Another practice, direct to consumer advertising, only became available once U.S. regulations opened that marketing channel. All of the practices involved, when examined through the lens of time, did in fact yield greater competitive results and greater efficiencies, but also had the unintended result of undermining customer relationships. This case study will look at those business practices in detail in the Results section of this paper.

The methodology used is driven by the study question: Over the past 35 years, what competitive business practices instituted by the pharmaceutical industry intended to drive increased competitiveness and business efficiencies had the unintended results of increasing the publics' general distrust and dissatisfaction with the industry? The methodology describes the underlying proposition along with the units of analysis employed by the study. Details of the methodology can be found in the next section of this paper under the heading Methods.

The results suggest the five changes in business practices have helped to improve competitive advantage and business efficiencies. The positive impact of these practices were demonstrated by industry results and company performance in the marketplace which are easy to identify and document. The five business practices which contribute to those results and which are often treated as proprietary information, took additional research to uncover. However, the unintended negative impact of these five practices on customer relationships could only be seen in retrospect and have also been documented.

In terms of theory, when focusing on business results, could the unintended consequences of the practices in question have been anticipated, limited or avoided? Since the changes in practice were driven by different functions in the pharmaceutical companies, was there any way to communicate across functional silos to determine the cumulative impact these practices would have on customer confidence and trust? Are there other industries which when attempting to improve competitiveness and efficiencies, also experienced customer distrust and dissatisfaction? In fact, the study found that in addition to the pharmaceutical industry, the airline, fast food and data technology industries have also improved their competitiveness and efficiencies but at considerable cost to customer trust and satisfaction - including government regulation.

When translated into actual practice the question becomes what considerations, questions or possibly metrics could be developed to analyze unintended fallout from changes in operational business practices? One of the fundamental precepts of brand management is to "attack oneself" as a competitor would in order to identify potential areas of weakness or opportunity. Should a similar approach be used when considering fundamental changes in business practices? The study conclusions suggest further research is needed to explore the practical considerations which should be discussed and evaluated to ascertain whether the intended benefits, i.e., increased competitiveness and efficiency, offsets possible risks to customer relations, company reputation and the possibility of government intervention. 


\section{Case Presentation}

\subsection{Methods}

This is a qualitative analysis using case study methodology (Yin, 2004, pp. 21-28). The study attempts to answer the question: Over the past 35 years, what competitive business practices instituted by the pharmaceutical industry intended to drive increased competitiveness and business efficiencies had the unintended results of increasing the publics' general distrust and dissatisfaction with the industry? The underlying proposition of the study is that by pursuing competitive advantage and improving sales and marketing efficiencies, the pharmaceutical industry experienced unintended consequences undermining customer relationships. The unit of analysis the study uses are changes in business practices - specifically five disparate business practices as described below:

1. Reliance on pharmaceutical marketers with MBAs but limited or no practical pharmaceutical selling experience.

2. The loss of independent pharmacies and pharmacists as customers due to the rise in national pharmacy chains.

3. Purchase and use of physician-specific prescribing data

4. Use of direct to consumer advertising for prescription drugs

5. Delaying generic competition and providing industry support for the Affordable Healthcare Act in exchange for U. S. government prohibition against the importation of prescription drugs into the U.S. from lower cost countries and prohibiting negotiated Medicare drug prices.

As stated earlier, when companies change their business practices, for competitive reasons they are generally not made public and only emerge over time. Since the underlying proposition of this case study is based on changes in business practices, it is important to find and link supporting data regarding those practices. Historical documents and publications were used to verify the implementation of the practices, while data and public reaction to the pharmaceutical industry's use of these practices provided the criteria for interpreting the results.

Additionally the author, having spent over 25 years in the pharmaceutical industry, has first hand knowledge of the practices described within this article. Additional input was provided by industry colleagues who also experienced the industry practices analyzed in this article (see Acknowledgments).

\subsection{Results}

\subsubsection{The Selling Process}

In order to appreciate the impact of the business practice analyzed in this study, it is helpful to understand the pharmaceutical selling process. Pharmaceutical sales are a complex process developed over decades by the industry (Greene, 2004). The person who decides what product to use (the doctor) is not the person who actually uses the product (the patient), nor are they the person who provides the product (pharmacist), who is also not necessarily the person who pays (payer) for the product (insurance companies, Medicare, Medicaid or the patient). The pharmaceutical selling process requires a multi-tiered approach with different interactions and potential conflicts between the interested customer groups.

Historically, pharmaceutical sales representatives ("reps") called on physicians and pharmacists promoting their company's products based on their Federal Drug Administration (FDA) approved indications. The reps usually called on a regular basis on their assigned physicians and pharmacists. Frequently reps built strong business relationships with many of their customers based on credibility, mutual respect and the use of meaningful scientific data. This is not to suggest there were reps who did not follow the rules or did not go too far in promoting their company products. In fact, there have been many instances of reps using inappropriate and unethical tactics to meet their sales quotas which has repeatedly raised concerns regarding pharmaceutical selling practices (Elliott, 2006).

New sales reps with little or no pharmaceutical sales experience would begin their career by calling on General Practitioners and Family Medicine doctors. These reps were often referred to as "Office Reps". While this practice would vary by company and product line, after several years a successful rep in this role would often be considered for promotion into what was frequently referred to as a "Specialty Rep" position. Depending on the company product lines, this might include specialty product sales for hospitals, oncology, rheumatology, cardiology, pediatrics, etc. An important outcome of this development process was that specialty reps, particularly those calling on physicians who were influencers of other physicians or who conducted clinical research, would develop relationships with these influential customers. 


\subsubsection{Practice \#1: The Rise of the Pharmaceutical Marketing MBAs}

Sales forces are the tool pharmaceutical companies use to promote their products to their customers. Product Managers, Portfolio Managers or Marketing Managers (the titles and scope vary by company) whose expertise help craft product positioning, pricing, promotional activities and support further product indications, drive product strategies. Prior to the popularity of MBAs in the 1980s, the marketers' experiences as sales representatives influenced the industry's product promotional strategies. Working with sales management, they would partner on sales strategies and tactics. The traditional path into a marketing or product management position required the marketer to spend time as a sales rep for a number of years - often as a specialty rep, even if that experience was with another pharmaceutical company. The idea behind this practice was intended to ensure that marketers understood the nuances and process of building the relationship sales reps developed with their physicians and enabled marketers to leverage their existing relationships with influential physicians. Even with those experiences, there has often been a certain level of creative tension between the sales and marketing functions which on occasion were not always in agreement regarding promotional tactics and strategies.

Enter the MBAs which were not a new concept in the 1980s. In fact the first such degrees were conferred in the early 1900 s and the perceived value of such a degree in producing future business leaders was highly questionable. Early reports of MBA curricula put the course content at the level of "Trade Schools" and academia was challenged to provide serious scientific rigor to their MBA programs. In 1963 about 5,800 MBAs were awarded. Rising to the challenge, colleges and universities offering MBA degrees added social sciences, behavioral sciences, mathematics and finance courses to their curricula so that by 1986, 67,000 MBA degrees were conferred (Mastering business, to a degree, 1916, 1989).

While colleges and universities across country expanded their MBA offerings and strengthened course content, the MBA curricula were designed to teach general business administration practices to their learners. By the 1990s over 700 universities provided Masters Degrees in generic business administration practices. However, only two universities offered an MBA focused on the pharmaceutical industry: St. Joseph's University in Philadelphia and Farleigh Dickinson in Rutherford, New Jersey. One pharmaceutical advertising executive stated: "No other industry has product managers with so little experience in their field." He made the point "that a lack of educational programs in pharmaceutical marketing has at times led to pharmaceuticals being marketed like consumer products, creating problems with regulatory agencies" (Hodnett, 1992).

As a result individuals with Master's Degrees in Business Administration with a focus on pharmaceutical marketing were considered valuable resources who could bring modern marketing practices to an industry ready for new products requiring new marketing techniques. Having spent time and money pursuing a pharmaceutical marketing MBA, many of these newly minted MBAs did not want to spend a great deal of time as pharmaceutical sales representatives. Initially many companies wanted their new MBAs to spend some time working as a sales representative before taking on a responsible marketing position (Hodnett, 1992).

In order to attract pharmaceutical focused MBAs and remain competitive in the marketplace this requirement to work as a sales representative for some limited period of time started to be seen as less relevant. The practice shifted to where a new MBA would work in the field with an existing sales reps on a periodic basis. The powers that be believed this approach would be sufficient to provide an appropriate appreciation of the relationship and process that developed between pharmaceutical sales reps and their customers. While most marketers got it, many did not, and the results undervalued the importance of the sales representative - physician relationship.

\subsubsection{Practice \#2: The Rise of National Retail Pharmacy Chains}

For the first three quarters of the 20th century, the majority of Americans obtained their prescriptions from local independent pharmacies. Many of these independent pharmacies were members of larger buying groups or independent franchisees of national chains such as Rexall Drugs which included over 11,000 drug stores by 1958 (Kovalchik, 2012). During the 1980s and 1990s large retail pharmacy chains purchased many of these independent pharmacies. The rise of Rite Aid $\AA$, CVSTM, Walgreens ${ }^{\mathrm{TM}}$ and others gained momentum during that period and continues to this day.

During the days of the independent pharmacies, depending on their product lineup, the industry practice was for pharmaceutical sales reps to call regularly on local pharmacies and work with the pharmacists to sell branded and generic prescription products as well as over-the-counter proprietary products. The reps built relationships with their pharmacists and as a result were often able to determine which physicians were writing which prescriptions. The practice allowed many reps to focus their selling efforts more efficiently by calling on the appropriate physicians in 
their territories. Many sales representatives built close relationships and a successful business partnership with these pharmacy owners and their employees.

The pharmaceutical industry, while not driving the transition from independent pharmacies to national chains, clearly benefited from the transition and played a role in this change. Bulk pricing allowed national chains to purchase large amounts of pharmaceutical products at prices which traditional independent pharmacies could not compete. The national purchasing contracts pharmaceutical companies created with the national chains made sales more predictable, reduced costs and more importantly meant that their sales reps no longer needed to call on the retail outlets of these chain stores. Instead, companies would have specialty reps or contracting departments' who had unique expertise in contracting to negotiate volume pricing and who would work with the purchasing agents in the regional or national headquarters of these retail pharmacy chains.

Most pharmaceutical reps stopped building relationships with retail pharmacists unless they had some independent pharmacies in their territory. This lack of a relationship between a pharmacist and a pharma sales rep meant both parties were not invested in each other's success to the same degree since the relationship became more transactional and less based on relationships. Loyalty to the pharmaceutical industry between the industry reps and their pharmacist customers which had been built over decades, began to disappear.

\subsubsection{Practice \#3: Data, Data, Data}

As access by reps to prescribing information at the pharmacy level became more difficult due to the growth of pharmacy chain stores, information technology and data collection systems were improving in accuracy and cost effectiveness. During the latter half of the 20th century the primary supplier of prescription prescribing data to the pharmaceutical industry came from a company known as Intercontinental Medical Statistics (IMS Health Inc., which recently merged with Quintiles to create IQVIA). Today IQVIA is the largest provider of pharmaceutical data to the healthcare and pharmaceutical industries. IMS was originally founded in 1954 based on the premise that there was a significant "need for drug market data" (Fundinguniverse.com, 2019). From its inception IMS developed numerous market audits of the drug industry. In the 1970s and 1980s it introduced Drug Distribution Data (DDD), which, for annual subscriptions, provided valuable physician prescribing data. The data was often grouped together in geographic areas along zip codes and were known as "bricks". The purpose was to allow the industry to have an idea of the geographic location of prescribing physician's without revealing specific physician prescribing habits.

By the 1990s companies like IMS Health, Dendrite, Verispan and others were providing script tracking data which provided very specific physician prescribing information (Fugh-Berman \& Ahari, 2007). This level of data proved informative. Patient information was removed from the data, but now the pharmaceutical companies knew almost every prescription physicians were writing outside of the hospital setting.

Looking for new business opportunities, the pharmaceutical industry saw the availability of this level of detailed data as a fundamental way to change their promotional strategies. This was the beginning of the mega sales forces for the pharmaceutical industry. From 1995 to 2005, the number of sales reps increased from 38,000 to 100,000 - an increase of over 160\% (Paul, 2005).

Previously, one sales rep might call on one general practitioner and promote anywhere from one to three products (sometimes more). However, with specific physician prescribing data, companies began sending two or more reps to speak with a single physician, each promoting a single product. Multiple reps called on one physician, each rep promoting just a single indication for the same product. Physicians' offices were so inundated with sales reps there were frequently more sales reps in a doctor's waiting room than patients (Elliott, 2006). As a result there was a significant pushback from the medical community which severely limited the number of sales reps doctors would see and in some cases stopped seeing pharmaceutical sales representatives altogether. This further eroded the relationship between the industry and their key customer base - prescribing physicians.

\subsubsection{Practice \#4: Direct to Consumer Advertising}

The fourth business practice to change was the introduction of Direct to Consumer (DTC) advertising in print media (Ventola, 2011). This was later followed with television DTC in 1993 when the FDA provided additional regulatory guidelines regarding pharmaceutical DTC advertising (Mogull, 2015). Initially companies like Pfizer began by promoting their company brand - not specific products. Over time the advertising shifted to "condition" advertising with no product mention, but a request to consumers to ask their physician about new treatments in a specific therapeutic area. Ultimately the focus shifted to specific prescription products. This was a huge change in the pharmaceutical selling model. "While the majority of pharmaceutical promotional expenditures (were) still aimed at physicians, spending on direct-to-consumer advertising of prescription drugs increased dramatically from $\$ 166$ 
million in 1993 to $\$ 4.2$ billion in 2005 and now makes up nearly 40 percent of total pharmaceutical promotional spending" (Donohue, 2006). As a result, the pharmaceutical industry soon became one of the top industries advertising their products on TV and in magazines. The United States and New Zealand are the only countries where direct to consumer advertising of prescription pharmaceuticals is permitted (Paek et al., 2011).

Advertising which promoted the use of a prescription product for a specific illness and which then preceded to list the numerous side effects which sometimes seemed worse than the illness itself often bewildered consumers. Regardless, consumers started to demand certain products from their physicians which strained the physician-patient relationship and strained the physician-pharmaceutical industry relationship. All of a sudden patients were asking for products which may or may not be suitable for them, which prior to this time, they were largely unaware. "Doctor Shopping" to find physicians who would prescribe the products patients wanted, irrespective of appropriateness, rose to levels previously unseen.

Prior to the advent of DTC advertising, the pharmaceutical industry kept a fairly low profile with regard to the public. Pharmaceutical stocks were traditionally seen as blue chip stocks purchased by institutional investors and retirees. They often provided a regular stream of dividend income and steady appreciation in equity price. America's opinion of the pharmaceutical industry soon changed due to high visibility provided by broadcast advertising. What had been a business-to-business selling process, now included a business-to-consumer model for prescription drugs. The industry had plenty of experience selling their non-prescription healthcare products to consumers, but the shift to marketing prescription products to the public, was entirely new.

The conditions for a "perfect storm" were developing: strained rep-physician relationships, decreasing rep-pharmacist interactions, high public visibility to the industry and the growing concern over drug prices.

\subsubsection{Practice \#5: Prescription Drug Pricing Policies}

Pharmaceutical pricing policies have had a profound effect on the public's perception of the industry. While an entire study could delve into this one issue, it appears there are 3 aspects of drug pricing that stand out in the public's eye as highly questionable.

\subsubsection{Drug Pricing}

Most Americans understand that drug prices outside the United States are significantly less than those for the same drugs purchased in the United States. A Drugwatch.com article from January 2018 reported that prescription drugs in eight regulated countries cost 56\% less than in the United States (Miller, 2018). The data, based on an analysis by IHS Markit can be seen in Figure 1 (IHS Markit, 2018).

\section{Prescription Drug Cost Savings}

Average percentage saved outside the U.S. for select prescriptions
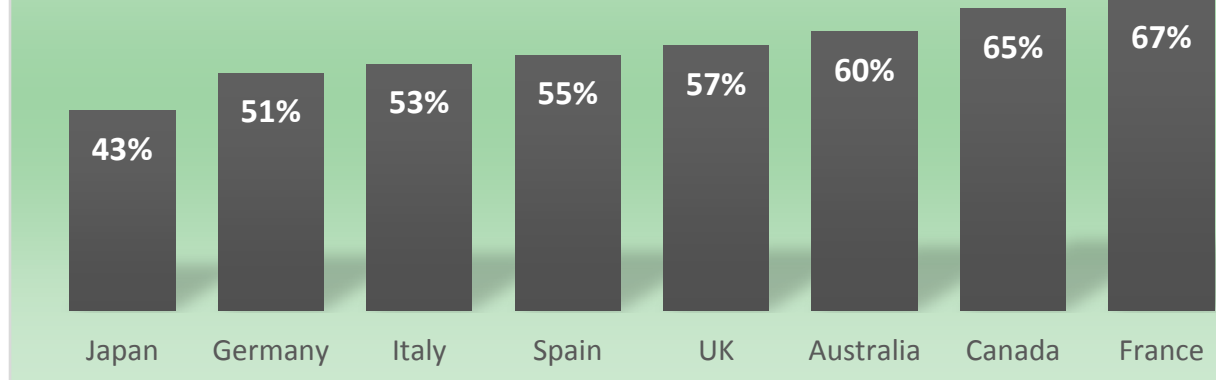

Figure 1. 2017 prescription drug cost savings in eight regulated markets

Source: IHS Markit POLI

In addition, the provision that would have allowed the importation of less costly drugs from Canada was dropped from the Affordable Care Act (ACA) in order to gain pharmaceutical industry support of the Act (Brill, 2015, pp.128-129) (Starr, 2013, pp. 204-206). Despite that fact, the Kaiser Foundation estimates that 19 million Americans 
(8\% of the U.S. population) import prescription drugs from outside the United States because of the significant cost savings - even though importation of these drugs is considered illegal ("Kaiser Health Tracking Poll: November 2016," 2017).

One of the arguments the industry cites to justify high drug prices, is the legitimate increase in the cost of new drug development and research. Yet, the British Broadcasting Company (BBC) reported information from Global Data showing that in 2013, nine out of the ten big pharmaceutical companies spent more on sales and marketing than research and development (Anderson, 2014).

\subsubsection{Delaying Generic Competition}

Pharmaceutical companies have found several ways to delay generic competition. One is to take old drugs and modify them slightly in order to extend a patent or even create a new patent which delays generic competition. This can drive significant price increases for old products - think insulin and epinephrine, old products which have seen unprecedented price increases in recent years (Rosenfeld, 2019) (Wang, Plunk and Morales, 2018).

Another effective strategy to delay generic competition is the legal ability for pharmaceutical companies to pay competitors not to launch a generic product once the innovator's patent has expired, known as "pay to delay". This tactic has raised significant ethical and legal questions. Pay to delay occurs when a generic competitor to the original innovator of a patented drug begins its FDA application to gain a license to market the generic. This process often begins prior to the actual patent expiring, which provides an opportunity for the innovator to sue the generic competitor. To make the suit go away, instead of the competitor paying damages, the innovator forgoes any damages and through a settlement, pays the generic manufacturer an undisclosed sum to delay the introduction of the generic product. This deprives the public of the lower cost generic and for all intents and purposes increases the product exclusivity of the originator (Hemphill, 2006). According to BioPharm International, pay to delay settlements delayed generic competition by 17 months when compared to settlements which do not include pay to delay payments (Greb, 2011).

\subsubsection{Negotiated Drug Pricing}

In order to gain pharmaceutical industry support of the ACA, Medicare drug price negotiation (not price regulation, but price negotiation) was specifically not included in the ACA, (Brill, 2015, pp.128-129) (Starr, 2013, pp.204-206) - even though a negotiated drug price contract for the United States Military and the Veterans Administration known as the Federal Supply Schedule already exists.

These pricing and competitive strategies have created a significant perception within the public's mind of corporate greed by the pharmaceutical industry. When coupled with the previous four practices described in this article, an environment has been created by the industry which has eroded credibility, trust and confidence as well as undermined the relationships between the four key customer groups which the industry had worked so hard to create in the first place: physicians, pharmacists, patients and payers.

\section{Discussion}

The short term quarterly demands of shareholders contribute to a certain level of short term thinking within a company. As a result businesses feel a constant pressure to improve efficiencies, increase market share as well as sales and profits. While certainly not a bad thing in itself, the short term focus can blind organizations to the long-term consequences of greater efficiency at all costs. Today's technology, especially the use of social media, make such missteps glaringly obvious and in time frames that make it difficult for companies to manage the narrative.

Was the drive for increased competitiveness and efficiencies along with the unintended consequence of undermining customer confidence unique to the pharmaceutical industry? As it turns out the answer is "No". For example, looking at the airline industry, the constant competitive pressures to reduce seat cost per mile has created a very negative flying experience for customers. All classes of customers, frequent flyers and occasional flyers, experienced long delays, being stuck on the tarmac on delayed flights with no food, water or access to toilets. Despite industry pushback, the situation had become so dire that in 2011, regulatory intervention resulted in what is called the Airline Passenger Rights which was further updated in 2016 (Tang, 2016).

In the fast food industry, the pursuit for the cheapest hamburger or piece of chicken led to production processes that when shared with the public through books such as Fast Food Nation (Schlosser, 2012), and The Omnivore's Dilemma (Pollan, 2016), were seen as highly questionable and even dangerous. The fact that the fast food industry helped shape how food is produced and sold in supermarkets, also undermined customers' trust in these industries. 
While the regulatory impact was minimal, the loss of trust resulted in practice changes in both the fast food industry as well as in the grocery industry. Customer pressure to provide products that are produced humanely, more organically, locally and with greater transparency have forced both industries to make significant changes in their production processes.

Even in the technology space, the pursuit to squeeze every last penny from customer data, has resulted in a significant loss of customer trust and increased regulatory pushback on data privacy. In Europe, data privacy regulations are based on the idea that the individual owns their own data while in the United States different parts of an individual's data is considered owned both by the individual and whoever else may hold the data (Myers, 2012). Despite assurances from technology companies regarding the security of their customers' data, the public is very skeptical and suspicious regarding industry's use of, and ability to secure, private data. Not to mention the numerous data breaches that most companies have experienced at one time or another. While the long term impact these concerns and actual privacy violations is still uncertain, clearly a suspicious and mistrustful public can push for policy or even regulatory changes whose costs are not simply financial - they could have impact how a business is required to operate.

Returning to the pharmaceutical industry, we see that regulatory controls in Europe have had an impact on the price of pharmaceutical products and the cost of promoting those products by limiting promotional activities (Mulinari, 2016). A primary reason for these regulatory limitations is that most countries in Europe have healthcare systems run by the government which needs to pay for their citizen's pharmaceutical needs. They recognize that unlimited promotion and pricing will cost their national healthcare budgets more than their taxpayers can support. While more research is needed, anecdotal reports such as this suggest that when customer relations are compromised and customer trust is lost, the risk of regulatory intervention as well as public pressure to change business practices, may increase significantly.

As seen in the industries cited earlier, once customer trust and relationships have been undermined, the apparent risk of regulatory intervention increases significantly. According to OpenSecrets.org, the lobbying arm of the pharmaceutical industry known as PhRMA (Pharmaceutical Research and Manufacturers of America) spent just under \$28 million to support their lobbying efforts in 2018. The combined lobbying expenditures of individual companies in the industry exceeded $\$ 254$ million in 2018 (Opensecrets.org, 2019). When it comes to lobbying efforts both PhRMA and the individual companies within the industry generally use two overarching strategies: one is to enhance the industry's image through educational and informational initiatives which supports their advocacy efforts regarding specific issues. The second is to lobby against any regulations which:

1. Allows the Department of HHS to create a negotiated formulary for Medicare (Medicare Monday: How Successful Negotiation Takes Place in Medicare, n.d.)

2. Limit intellectual property rights (Wilbur, 2016)

3. Stop "Pay to Delay" settlements (Controversy swirls around pay-for-delay deals, 2011)

While many insiders within the industry privately admit that some (if not all) of these changes are probably inevitable, for the time being the industry feels it worthwhile to continue the fight and delay regulatory intervention as long as they can. With that in mind, until the pharmaceutical industry is successful in finding new ways to rebuild its customer relationships, the distrust and lack of confidence the public has with the industry is likely to continue for the foreseeable future.

\subsection{Conclusions}

This study documented the implementation of the five practices put forward. It also demonstrated that each of those practices, which while seemingly unrelated, had the unintended consequence of negatively impacting one or more customer groups. The pursuit of greater business efficiencies, increased market share, sales and profits are a regular focus in profit driven businesses. The pharmaceutical industry is no different. When business practices which drive those objectives slowly erode customer relationships, what are the consequences? In this case the pharmaceutical industry has seen an increase in all of its customer groups demanding changes to pricing and generic competition whether implemented voluntarily by the industry or through government regulation.

As stated earlier, one of the biggest limitations in developing this case study is that by their very nature, changes in business practices are often seen as proprietary and not generally reported in the press or industry publications until some time after their implementation and once their impact can be evaluated. Other than internal company documents, business practices can be very difficult to research. It is only after several companies adopt similar practices, that these methods are identified and seen as common practice. 
Another limitation of the study is its inability to measure the degree of customer dissatisfaction. Since companies continue to sell their products and remain profitable, one school of thought would say the companies are still highly successful. Until the level of dissatisfaction voiced by customer groups results in significant changes, either through voluntary or government intervention, it could be argued the level of dissatisfaction is not yet of real consequence.

When looking at the other industries which experienced loss in customer confidence, this study did not look at any specific practices of those industries. The study simply consolidated their overall efforts to drive greater efficiencies in order to increase profits. Additional research into the specific practices of those industries to generate those greater efficiencies, might again yield insight into several practices which seem unrelated, yet have the unintended potential of undermining customer confidence.

The implications of this unique analysis for both researchers and practitioners suggests that when seemingly isolated tactical improvements in business practices are implemented, broader strategic analysis and cross organizational conversations should take place in an effort to identify possible unintended consequences which might result from those changes in practice. The timing and content of those conversations in relation to the development and implementation of changes in business practices needs to be further researched. In addition, further research is needed to potentially establish criteria for driving the content discussion(s) when holding such cross functional strategic discussions.

\section{Acknowledgements}

Special thanks to Irwin Gellman Esq. for patiently providing extensive editing feedback. Additional input from Gardy Bonny and David Lobenberg, RPh, colleagues who provided additional first hand information regarding their pharmaceutical industry experiences with the business practices examined in this analysis.

\section{References}

Anderson, R. (2014, November 6). Pharmaceutical industry gets high on fat profits. BBC News. Retrieved from https://www.bbc.com/news/business-28212223?

Brill, S. (2015). America's bitter pill money, politics, backroom deals, and the fight to fix our broken healthcare system (pp. 128-129). New York, N.Y.: Random House.

Controversy swirls around pay-for-delay deals. (2011). Chain Drug Review, 33(1), 63. Retrieved from https://go-gale-com.ezproxy.ithaca.edu/ps/i.do?id=GALE\%7CA245883713\&v=2.1\&u=nysl_sc_ithaca\&it=r\&p $=\mathrm{AONE} \& \mathrm{SW}=\mathrm{W}$

Donohue, J. (2006). A History of Drug Advertising: The Evolving Roles of Consumers and Consumer Protection. The Milbank Quarterly, 84(4), 659-699. https://doi.org/10.1111/j.1468-0009.2006.00464.x

Elliott, C. (2006, April). The drug pushers. Retrieved July 19, 2019, from https://www.theatlantic.com/magazine/archive/2006/04/the-drug-pushers/304714/

Fugh-Berman, A., \& Ahari, S. (2007). Following the Script: How Drug Reps Make Friends and Influence Doctors. PLoS Medicine, 4(4), e150. https://doi.org/10.1371/journal.pmed.0040150

Greb, E. (2011). Pay-to-delay deals. Retrieved July 2, 2019, from http://ezproxy.ithaca.edu:2048/login?url=https://search-proquest-com.ezproxy.ithaca.edu/docview/879814213?a ccountid $=11644$

Greene, J. A. (2004). Attention to 'Details': Etiquette and the Pharmaceutical Salesman in Postwar American. Social Studies of Science, 34(2), 271-292. https://doi.org/10.1177/0306312704043029

Hemphill, C. (2006). Paying for delay: Pharmaceutical patent settlement as a regulatory design problem. Retrieved from https://www.nyulawreview.org/wp-content/uploads/2018/08/NYULawReview-81-5-Hemphill.pdf

History of IMS Health, Inc. - FundingUniverse. (2019). Retrieved May 24, 2019, from http://www.fundinguniverse.com/company-histories/ims-health-inc-history/

Hodnett, J. (1992). Want an MBA in pharmaceutical marketing?. Medical Marketing \& Media, 27(10), 60. Retrieved from

https://go-gale-com.ezproxy.ithaca.edu/ps/i.do?id=GALE\%7CA13600363\&v=2.1\&u=nysl_sc_ithaca\&it=r\&p= AONE\&sw $=\mathrm{w}$

Kaiser Health Tracking Poll: November 2016. (2017, January 3). Retrieved July 13, 2019, from http://files.kff.org/attachment/Kaiser-Health-Tracking-Poll-November-2016-Topline

Kovalchik, K. (2012, July 11). 11 Defunct Drugstore Chains. Retrieved May 26, 2019, from http://mentalfloss.com/article/31166/11-defunct-drugstore-chains 
Lobbying Spending Database Pharmaceuticals/Health Products, 2019 | OpenSecrets. (2019). Retrieved July 2, 2019, from https://www.opensecrets.org/lobby/indusclient.php?id=h04\&year=2018

Mastering Business, to a Degree, 1916. (1989). Wall Street Journal, Centennial Journal: 100 Years in Business, B1. Retrieved from https://ilene.ithaca.edu/illiad/illiad.dll?Action=10\&Form $=75 \&$ Value $=269656$

Miller, E. (2018, January 25). US Drug Prices vs The World. Retrieved July 13, 2019, from https://www.drugwatch.com/featured/us-drug-prices-higher-vs-world/

Mogull, S. A. (2015). Chronology of Direct-to-Consumer Advertising Regulation in the United States. Retrieved December 18, 2018, from https://www.academia.edu/278465/Chronology_of_Direct-to-Consumer_Advertising_Regulation_in_the_Unite d_States

Mulinari, S. (2016). Regulating Pharmaceutical Industry Marketing: Development, Enforcement, and Outcome of Marketing Rules. Sociology Compass, 10(1), 74-86. https://doi.org/10.1111/soc4.12335

Myers, C. (2012). Digital Immortality vs. "The Right to be Forgotten": A Comparison of U.S. and E.U. Laws Concerning Social Media Privacy. Romanian Journal of Communications and Public Relations, 16(3), 47-60. Retrieved from https://journalofcommunication.ro/index.php/journalofcommunication/article/view/175/177

Paek, H.-J., Lee, H., Praet, C., Chan, K., Chien, P. M., Huh, J., \& Cameron, G. (2011). Pharmaceutical Advertising in Korea, Japan, Hong Kong, Australia, and the US: Current Conditions and Future Directions. In Pharmaceutical Advertising in Korea (p. 5). Retrieved from https://www.academia.edu/3848441/Pharmaceutical_Advertising_in_Korea_Japan_Hong_Kong_Australia_and _the_US_Current_Conditions_and_Future_Directions

Paul, C. M. (2005). Rep tide pulling back in magnitude, pushing forward efficiency: recent talk of pharma companies restructuring or even paring back their sales forces is the first acknowledgement that efficiency, and not noise, is the key to successful detailing. Medical Marketing \& Media, 40(8), 96. Retrieved from https://link-gale-com.ezproxy.ithaca.edu/apps/doc/A139429683/AONE?u=nysl_sc_ithaca\&sid=AONE\&xid=6a ac551f

PhRMA. (n.d.). Medicare Monday: how successful negotiation takes place in Medicare. Retrieved from http://phrma-docs.phrma.org/sites/default/files/pdf/medicare-monday-negotiation.pdf

Pollan, M. (2016). The omnivore's dilemma : a natural history of four meals (Original work published 2006). New York: Penguin Books.

Rosenfeld, J. (2019). The rising price of insulin. Medical Economics, 96(7), 45-47.

Schlosser, E. (2012). Fast food nation: the dark side of the all-American meal (Original work published 2001). Boston: Mariner Books/Houghton Mifflin Harcourt.

Starr, P. (2013). Remedy and reaction : the peculiar American struggle over health care reform (pp. 204-206). New Haven: Yale University Press.

Tang, R. (2016). Airline Passenger Rights: The Federal Role in Aviation Consumer Protection. Retrieved from https://fas.org/sgp/crs/misc/R43078.pdf

To make better decisions, you need to see the big picture. (2018). Retrieved July 13, 2019, from https://ihsmarkit.com/solutions/us-price-gouging-pharmaceutical-industry.html

Ventola, C. L. (2011). Direct-to-Consumer Pharmaceutical Advertising: Therapeutic or Toxic?. $P$ \& T: A Peer-Reviewed Journal for Formulary Management, 36(10), 669-684. Retrieved from https://www.ncbi.nlm.nih.gov/pmc/articles/PMC3278148/

Wang, E., Plunk, A., \& Morales, M. (2018). Attitudes and beliefs toward epinephrine auto-injector price increase. Annals of Allergy, Asthma \& Immunology, 121(5), S58. https://doi.org/10.1016/j.anai.2018.09.189

Wikipedia Contributors. (2019, August 6). Direct-to-consumer advertising. Retrieved May 24, 2019, from https://en.wikipedia.org/wiki/Direct-to-consumer_advertising

Wilbur, T. (2016). IP Explained: Myth vs. fact about strong patent protections in the biopharmaceutical industry. $\begin{array}{llll}\text { Retrieved } \quad \text { August 13, 2019, from } & \text { 13, }\end{array}$ https://catalyst.phrma.org/ip-explained-myth-vs.-fact-about-strong-patent-protections-in-the-biopharmaceuticalindustry

Yin, R. K. (2004). Case study research : design and methods (3rd ed., pp. 21-28). Thousand Oaks ; London ; New Delhi: Sage. 